\title{
Self-Efficacy of Filipino Senior High School Students: Differences Among Tracks/Strand and Type of School
}

\author{
Jonas Villas \\ Mathematics Unit, College of Education, Leyte Normal University, Tacloban City, Philippines
}

\begin{abstract}
The study sought to determine the self-efficacy of Grade 11 senior high school students in the academic (mastery of experience, vicarious experience, verbal persuasion, and somatic-emotional states), and health component in an urban school in the Philippines. Using a ten-point self-efficacy scale, administered to a sample of 150 students from three public and three private schools in Quezon City, Metro Manila, the study reveals that senior high school students have a moderate level of self-efficacy. Also, the general self-efficacy of students does not differ across school type; however, a significant difference occurs within the component of self-efficacy, i.e., vicarious experience and verbal persuasion across school type. The analysis reveals that students from public schools have high self-efficacy level regarding vicarious experience as compared to students from private schools. On the contrary, students from private schools yield a much higher self-efficacy score than their counterpart in the verbal persuasion component of the self-efficacy scale. Also, a significant difference across tracks/strand occurs in the verbal persuasion component. As a conclusion, Grade 11 students have a moderate self-efficacy, implying that they are confident of succeeding academically. Second, for a homogenous group, age and self-efficacy are not associated. Third, merely belonging to a particular school and a specific track generates or boosts self-efficacy in one way or the other.
\end{abstract}

Keywords: self-efficacy, senior high school, Philippine education, K-12, test and scale

DOI: $10.7176 / \mathrm{JEP} / 10-8-02$

Publication date:March $31^{\text {st }} 2019$

\section{Introduction}

Perceived self-efficacy is centered on people's beliefs on their capabilities to produce given attainments (Bandura, 2006). As a theory, it tells us that "people generally will only attempt things they believe they can accomplish and will not attempt things they believe they will fail" (Brown, Malouff \& Shutte, 2013). In the context of schooling, self-efficacy is important as it is seen to be related to "higher achievement, better health and social integration (Schwarzer, 1992 \& Bandura, 1997).

The Philippines has implemented the Senior High School (SHS) program of the Department of Education (Dep.Ed.) across the country beginning School Year 2016-2017. This program is a two-year specialized secondary education. In these two years, Grades 11 and 12 students are allowed to choose a specialization based on their aptitude, interests, and capacity. There are four track options for the students to choose from: Academic; Arts and Design; Sports; and Technical-Vocational-Livelihood. The Academic track includes four strands; Accountancy, Business, and Management (ABM); Humanities and Social Sciences (HUMSS); Science, Technology, Engineering and Mathematics (STEM); and the General Academic (GA). Graduates of the K to 12 program are expected to have lifelong learning skills, competence to work and be productive, able to coexist in local and global communities, to engage in independent, creative and critical thinking and have the capacity and willingness to transform others and one's self (RA 10533, 2013).

Given this, the program has been a subject of several inquiries to ensure its success and to provide a mechanism of support for its improvement. As the curriculum is multi-faceted, most of the inquiries are centered on the competencies, the mode and the medium of instruction. These notion leads the researcher to look into the intrinsic characteristics of students which is vital in their motivation - in their drive to study and to progress in their academic endeavor. One of these intrinsic characteristics seen as an essential trait of students necessary in their academic endeavor is Self-Efficacy (Bandura, 1997, 2007; Schwarzer, 1992; \& Brown, Malouff \& Shutte, 2013).

The constructs of self-efficacy as a theory includes (1) mastery experience which refers to prior success at having accomplished something similar to the new behavior; vicarious experience which implies learning by watching someone similar to self that has been successful (Hayden, 2009); (3) verbal persuasion connotes encouragement by others; and (4) somatic and emotional states - the physical and emotional states caused by thinking about undertaking the behavior. Self-efficacy is also domain specific (Schwarzer, 1992). Therefore, this will capacitate the researcher to craft some statements concerning specific issues like, physical well-being which was also seen as vital in students success (Willeboordse, Jansen, Van den Heijkant, Simons, Winkens, De Groot, \& ... Oosterhoff, 2016; Lewallen, Hunt, Potts-Datema, Zaza, \& Giles, 2015; Badie \& Brown, 2010; \& Rasmussen \& Laumann, 2013). Such inclusion is supported by Bandura's (1997) notion of self-efficacy, conceptualized in a situation-specific manner and remains to be fundamental to self-efficacy scale construction. Relative to this, there 
is a need for the researcher to ascertain the scope of the self-efficacy scale to be constructed and administered.

Concerning item construction, Bandura (2006) emphasized that it should be phrased as "can do" rather than "will do." It was underscored that "can is a judgment of capability while the will is a statement of perception." The response scale used in Self-efficacy studies ranges from 5-interval scale to a "0-100" response format. It was shown in the study of Pajares, Hartley, and Valiante (2001) that the larger the interval scale, the more likely it can predict performance (Pajares, Hartley, \& Valiante, 2001).

It is on these premises that the researcher crafted a Self-Efficacy Scale constructed on a ten-point scale to assess academic and health self-efficacy of Senior High School students (Grade 11). The constructs identified by Bandura (2006) was used in item construction for the academic self-efficacy while the health component statements were crafted based more on general practices.

The primary objective of the study was to determine the self-efficacy of Grade 11 senior high school students. The following are the research questions of the study.

(1) What is the self-efficacy level of the grade 11 senior high school students in the following components?

a. Academic
i. Mastery Experience
ii. Vicarious Experience
iii. Verbal Persuasion
iv. Somatic Emotional State

b. Health

(2) Is there an association between age and students' self-efficacy?

(3) Is there a significant difference in students efficacy-level across:

a. Sex?

b. School Type?

c. Track/Strand?

Understanding the self-efficacy of grade 11 Senior high school students in performing academic and health activities will provide input on the improvement of teaching and learning practice in general. Specifically, the findings of the study will provide input to the school administrators in crafting interventions and opportunities that will promote the learning experience of the students as a whole. On the other hand, the teachers will be guided with the basic tenets of understanding their students, equipping them in the performance of immediate intervention in the class, a more differentiated approach to teaching, and remediation that will target both cognitive and affective domains promoting students' motivation towards learning. Also, the parents upon knowing how confident their children are in the conduct of academic and health activities will be able to provide a better support mechanism. Parents role are emphasized particularly in encouraging their children to perform well in school and vicariously provide an example of success through themselves to encourage their children further. Finally, the students, afforded with an assessment of how confident they are in performing academic and health activities, will be dawned in a reality that they have to face. In so doing, they will be able to establish their self-help efforts to boost their confidence and seek support mechanism from their peers, teachers, and family.

\section{Methods}

The study seeks to determine the self-efficacy of students and establish its relationship by association and difference between the students' demographic characteristics. The study is descriptive and follows the "most common descriptive methodology, survey" (Fraenkel and Wallen, 2009). It implores a quantitative technique particularly frequency counts, percentages and mean. Further, inferences were drawn based on the results of tests for the association on Pearson-Product Moment Coefficient (Pearson r) and test of differences: t-test for independent samples and ANOVA.

The scale used in the study is composed of 15 items constructed based on the "guide for constructing selfefficacy scales" by Bandura (2006). In this paper, the response format was a ten-point scale rather than a 5-interval scale. The researcher did not opt for a "0-100" response format as this may be in a way difficult for the respondents to apply in quantification to their confidence level in the conduct of activities explicated in the statements of the scale.

Content validation was done by an expert in Educational Research and Evaluation. The table of specifications (TOS) for the scale is shown in Table 1. The items were distributed in two subscales: academic and health component. The Academic component in the scale was developed following the constructs underscored in selfefficacy theory. On the other hand, items in the health component are more generalized based on observations and reported health practices among students.

Cronbach's alpha coefficient reveals that the reliability of the self-efficacy scale is 0.77 which can be considered as moderate (Salvucci, Walter, Conley, Fink, \& Saba, 1997) and acceptable (Pallant, 2004 \& George \& Mallery, 2003) in terms of consistency reliability. 
Table 1. Distribution of Items by Component

\begin{tabular}{cccc}
\hline \multicolumn{2}{c}{ Component } & No of Items & \% \\
\hline \multirow{3}{*}{ Academic } & Mastery Experience & $4(4,5,7,8)$ & 26.67 \\
Component & Vicarious Experience & $2(10,13)$ & 13.33 \\
& Verbal persuasion & $2(9,12)$ & 13.33 \\
Health Component & $4(3,11,14,15)$ & 26.67 \\
& Emotional State & $3(1,2,6)$ & 20.00 \\
\hline & Total & 15 & 100.00 \\
\hline
\end{tabular}

The items of the scale follow the stem "I Can..." as a judgment of capability (Bandura, 2006). A sample of these items under each component is presented in Table 2.

Table 2. Sample Items by Component

\begin{tabular}{lll}
\hline & Component & I Can... \\
\hline \multirow{3}{*}{ Academic } & Mastery Experience & Find errors in my own work. \\
& Vicarious Experience & Work well with my classmates. \\
& Verbal persuasion & Live up to people's expectations. \\
Health & Emotional State & Work under pressure. \\
& & Say no to junk food. \\
\hline
\end{tabular}

In this study, a total of 150 students served as the sample where the majority of them are female, e.g., 88 comprising $59 \%$, of the sample. In terms of age, most of the respondents $n=74 ; 49.3 \%$, are of age 16 . Table 3 shows the distribution of respondents by age.

Table 3. Distribution of Respondents by Age

\begin{tabular}{ccc}
\hline Age & Frequency & \% \\
\hline 15 & 28 & $19 \%$ \\
16 & 74 & $50 \%$ \\
17 & 34 & $23 \%$ \\
18 & 5 & $3 \%$ \\
19 & 3 & $2 \%$ \\
21 & 2 & $1 \%$ \\
31 & 1 & $1 \%$ \\
\hline Total & 147 & $100 \%$ \\
\hline
\end{tabular}

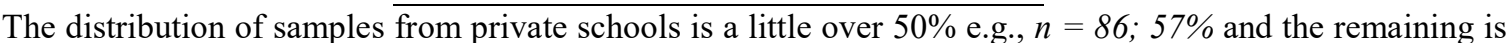
from public schools $(n=64 ; 43 \%)$. In terms of tracks/strand, most of the students are enrolled in the STEM, and ABS $(n=36 ; 24 \%)$ and only $8 \%(n=12)$ are enrolled in GAS. Figure 2 below shows the distribution of respondents by track/strand enrolled.

The study was conducted in three (3) public and three (3) private schools in Quezon City, Metro Manila. The number of students participating in each of these schools was 32,12, 20,31,26, and 29 respectively. The reason for this unequal representation is based on the unequal number of tracks/strand offered in each of this school and on the availability of the students during the data gathering process. The unequal representation will not pose a threat in the analysis as the grouping is made in terms of school type, and sex which may not be necessarily equal but at least closer in terms of frequency and on the exhaustion of all possible tracks/strand to be represented.

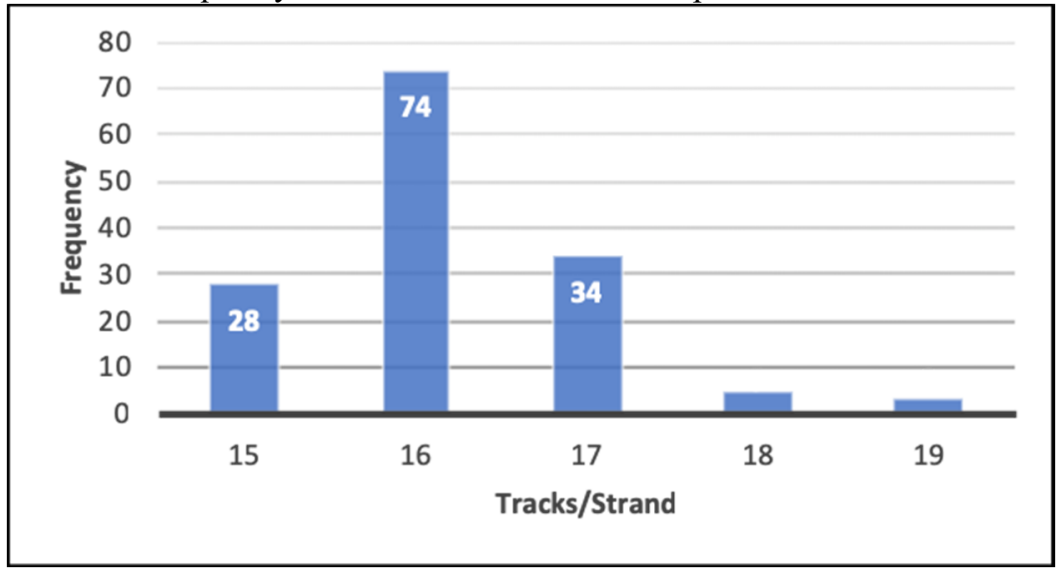

Figure 1. Distribution of Respondents by Track/Strand

Data were gathered in anticipation of the holiday break for the DepEd in October. A letter of request for the 
endorsement of the DepEd Quezon City Division through the office of the Division Superintendent was sought. After it was issued, letters to the principals were delivered, and the schedule of the data gathering was finalized. The data was gathered from the $10^{\text {th }}$ to the $14^{\text {th }}$ of October 2016 , and the venue was in their respective schools. The participants of the survey were gathered in a classroom, seated together by tracks/strand and were asked to sign an attendance sheet. The researcher then introduced himself and provided a background on what the study is all about. The questionnaires were then distributed and guided by the researcher, the directions were read, and the parts of the instrument were presented. The participants were asked if they have questions for clarification and if the directions are clear for them. After this, the participants answered the questionnaire. Each of the instruments was then scrutinized for quality check and to ensure no partial response.

The MS Excel software was utilized to automate the coding of the responses where the 10-point scale and respondent's age were no longer coded and is taken as it is. After the data was coded, the file was exported to a licensed statistical software which was made available to the researcher. Two statistical test or procedures were employed in data analysis. First was Pearson-Product Moment Coefficient (Pearson $r$ ) for the test of association between age and $t$ self-efficacy and test of differences: $t$-test for independent samples and ANOVA significant difference in students' efficacy-level across Sex, School type, and Track/Strand

\section{Results}

\subsection{Self-efficacy of Senior High School}

The self-efficacy of senior high school students was gleaned in two components academic and health. Under the academic component, items in the scale were grouped according to the construct mastery of experience, vicarious experience, verbal persuasion, and somatic emotional states. In this scale, both the health and academic component was gleaned to be vital and must go hand in hand for success in the academic endeavor.

The scale administered to $n=150$ Grade 11 Senior High School students reveals in general that the students are moderately confident in performing both academic and health-related activities. This finding indicates that they have a firm belief that they will be able to hurdle the challenges of their schooling. Table 4 shows the different self-efficacy levels of students across different components. It can be seen that though they are moderately confident in all components, performing tasks related to health is at the bottom of the scale followed by somatic and emotional states $(\bar{x}=6.48)$. Categorically, both are health-related as it centers on physical and mental wellbeing, i.e., in cases of handling stress or making the job done despite a stressful situation and on occasions of saying no to harmful health habits like eating junk foods. Scoring the lowest in the component indicates that there is in a way a need to revisit our practices of ensuring a healthy body and mind.

The table also shows that the students are much confident, that is if we put the components in ranks, in performing tasks that they have experienced already, evident by their mean score in mastery experience which is 7.89. This experience need not be a success all the time. We learn from our mistakes; in situations where we failed, it creates a drive for the individual to perform the same task in a correct manner (Zimmerman, 2000). Hence, most likely the confidence of an individual in the performance of such a task is also increased.

Table 4. Self-efficacy of Senior High School Students (Grade 11) in Selected Schools in Quezon City: SY 20162017

\begin{tabular}{ccc}
\hline Component & Self-efficacy Score \\
\hline \multirow{3}{*}{ Academic } & 7.89 \\
& Mastery of Experience & 6.87 \\
& Vicarious Experience & 6.76 \\
& Verbal Persuasion & 6.48 \\
Somatic and Emotional States & 6.46 \\
\hline Health Component & 7.88 \\
\hline
\end{tabular}

\subsection{Association of Self-Efficacy and Age of Senior High School Students}

It is understood that as one progress in age, he or she is most likely more confident in the performance of the task that he/she is confronted. In the parlance of education, an individual in a senior year is gleaned from being more confident in dealing with academic-related activities than those in lower years. The study hypothesized that an older individual would be more self-efficacious than a younger one. However, in this study, the results reveal a no significant association in the self-efficacy of students to their age.

Table 5 shows p-values greater than alpha 0.05 indicating no association. This may be anchored on the fact that the sample of the study is in a way homogenous in terms of age, where most of them are in the age range of 15-17years old. 
Table 5. Association of Age and Self-efficacy of Senior High School Students (Grade 11) in Selected Schools in Quezon City: SY 2016-2017

\begin{tabular}{clcc}
\hline Component & r & p-value \\
\hline Academic & Mastery Experience & 0.07 & 0.369 \\
& Vicarious Experience & 0.11 & 0.173 \\
Verbal Persuasion & -0.03 & 0.719 \\
Somatic and Emotional States & 0.07 & 0.381 \\
Health Component & 0.16 & 0.054 \\
\hline Total Self-efficacy & 0.11 & 0.177 \\
\hline
\end{tabular}

\subsection{Differences in Self-Efficacy Across Sex, School Type, and Track/Strand}

In this section, self-efficacy of students was tested for significant differences across sex, school type, and track/strand.

\subsubsection{Across Sex}

The test of significant difference, $t$-test for independent sample, yields p-values greater than alpha 0.05 indicating no significant difference in self-efficacy of students across sexes, as seen in Table 6 . These results are consistent with various studies (Kumar \& Lal, 2006; Tenaw, 2013; Zhang, Zhang, Liu, Zhang, Wang, \& Liu, 2015) saying that one's self-efficacy is not attributed to sex. On hindsight, this provides the notion of equal experience to be afforded to students regardless of their sex. This emphasizes that both sexes are equally confident to perform academic and health-related tasks.

Table 6. The difference in Self-efficacy across Sex of Senior High School Students (Grade 11) in Selected

Schools in Quezon City: SY 2016-2017

\begin{tabular}{clcc}
\hline Component & t-test (ind.) & p-value \\
\hline Academic & Mastery Experience & 1.35 & 0.181 \\
& Vicarious Experience & 0.94 & 0.349 \\
Verbal Persuasion & 1.22 & 0.226 \\
Somatic and Emotional States & 0.53 & 0.600 \\
Health Component & 1.11 & 0.267 \\
\hline Total Self-efficacy & 1.50 & 0.137 \\
\hline
\end{tabular}

\subsubsection{School Type}

An individual who belongs to a different organization may have experienced things that are distinct to that organization. During the school visits conducted by the researcher in public and private schools, there were several indicators of differences between public and private institutions catering to senior high school. One of the glaring differences is the school facilities. Private schools' facilities are already in place, structured and teachers are already familiar with its use. On the other hand, public schools are still in quandary of catching up with the procurement of these facilities and several of them are still in the process of constructing classrooms. This is a way impacts the teacher to innovate and bridge the gap in the lack of facilities, learning guides, references and even instruments used in TVL strand.

With this premise, it is hypothesized that self-efficacy of students from different school type: private and public schools, will differ. Table 7 shows the results of the test of significant difference. The t-test for independent samples reveals a significant difference of student's self-efficacy across school type only in components vicarious experience with p-value 0.036 and verbal persuasion with p-value 0.002 , both less than 0.05 level of significance. In general, putting into consideration all component of the scale, self-efficacy of students does not differ across school type evident by $\mathrm{p}$-value 0.868 greater than 0.05 level of significance.

Table 7. The Difference in Self-efficacy across School type of Senior High School Students (Grade 11) in Selected Schools in Quezon City: SY 2016-2017

\begin{tabular}{|c|c|c|c|}
\hline \multicolumn{2}{|r|}{ Component } & \multirow{2}{*}{$\begin{array}{c}\text { t-test (ind.) } \\
0.25\end{array}$} & \multirow{2}{*}{$\frac{\text { p-value }}{0.806}$} \\
\hline Academic & Mastery Experience & & \\
\hline & Vicarious Experience & 2.12 & $0.036^{*}$ \\
\hline & Verbal Persuasion & -3.14 & $0.002 *$ \\
\hline & Somatic and Emotional States & -0.62 & 0.537 \\
\hline \multicolumn{2}{|c|}{ Health Component } & 1.91 & 0.058 \\
\hline & Total Self-efficacy & 0.17 & 0.868 \\
\hline
\end{tabular}

Examining vicarious experience where a significant difference across school type was flagged, the mean selfefficacy of students from public schools is $\bar{x}=7.14 ; n=63$ while $\bar{x}=6.66 ; n=86$ for private schools. This shows that students from public schools have high self-efficacy level in terms of vicarious experience as compared to students from private schools. Vicarious experience is indicative that students are confident in performing a particular task 
because they have already seen someone who was victorious in the performance of such task (Bandura 2006). Could this be that because, during the time the study was conducted, there were no complete set of materials and facilities readily available for students, teachers by their very selves modeled the task to the students, showing how it can be succeeded and thus boosted the confidence of their students? The reason for this in general remains to be ambiguous and the context of the characteristics and specific experience afforded to students in both school types has to be determined in depth.

In the verbal persuasion component of the self-efficacy scale, students from public schools yielded a $\bar{x}=6.27 ; n=64$ while students from the private schools yielded a much higher self-efficacy score, i.e., $\bar{x}=7.12 ; n=86$ Verbal persuasion suggests that students who received verbal encouragement are most likely to be confident in the performance of the task of which he or she is encouraged to do so (Bandura, 2006). This implies that most likely, students from private schools received more encouragement from the people around them, e.g., family, teachers, classmates and friends than those from public schools. This also connotes the need for students in public schools to be encouraged further to boost their confidence in the conduct of academic and health-related activities.

\subsubsection{Track/Strand}

Ninety-Five percent of the students, i.e., 142 out of 150 claimed that the track or strand they are enrolled in was of their own choice. This in itself may suggest that $95 \%$ of the sample is confident to go about the task related to their choice of the strand/track. The test for a significant difference in self-efficacy of senior high school students across track/strand supports this notion with p-value 0.900 which is higher than 0.05 . It can be said that in general, students enrolled in different tracks are equally confident in the performance of academic and health-related tasks. However, upon inspection of each of the components, as revealed in Table8, a significant difference in self-efficacy of students across tracks occurs in the verbal persuasion component with p-value 0.028 less than 0.05 level of significance.

Table 8. The Difference in Self-efficacy across Tracks/Strand of Senior High School Students (Grade 11) in Selected Schools in Quezon City: SY 2016-2017

\begin{tabular}{|c|l|c|c|}
\hline \multirow{3}{*}{ Academic } & Component & F & p-value \\
\cline { 2 - 4 } & Mastery Experience & 0.26 & 0.902 \\
\cline { 2 - 4 } & Vicarious Experience & 0.26 & 0.905 \\
\cline { 2 - 4 } & Verbal Persuasion & 2.81 & $0.028^{*}$ \\
\cline { 2 - 4 } & Somatic and Emotional States & 1.46 & 0.218 \\
\hline Health Component & 0.56 & 0.691 \\
\hline Total Self-efficacy & 0.27 & 0.900 \\
\hline
\end{tabular}

*p-value $<0.05$ level of significance

Post Hoc analysis (Tukey HSD) reveals that this difference occurs between students enrolled in TVL and STEM with p-value 0.022 less than 0.05 level of significance. Figure 2 below shows the mean plots of Verbal Persuasion Self Efficacy Component by Tracks/Strand.

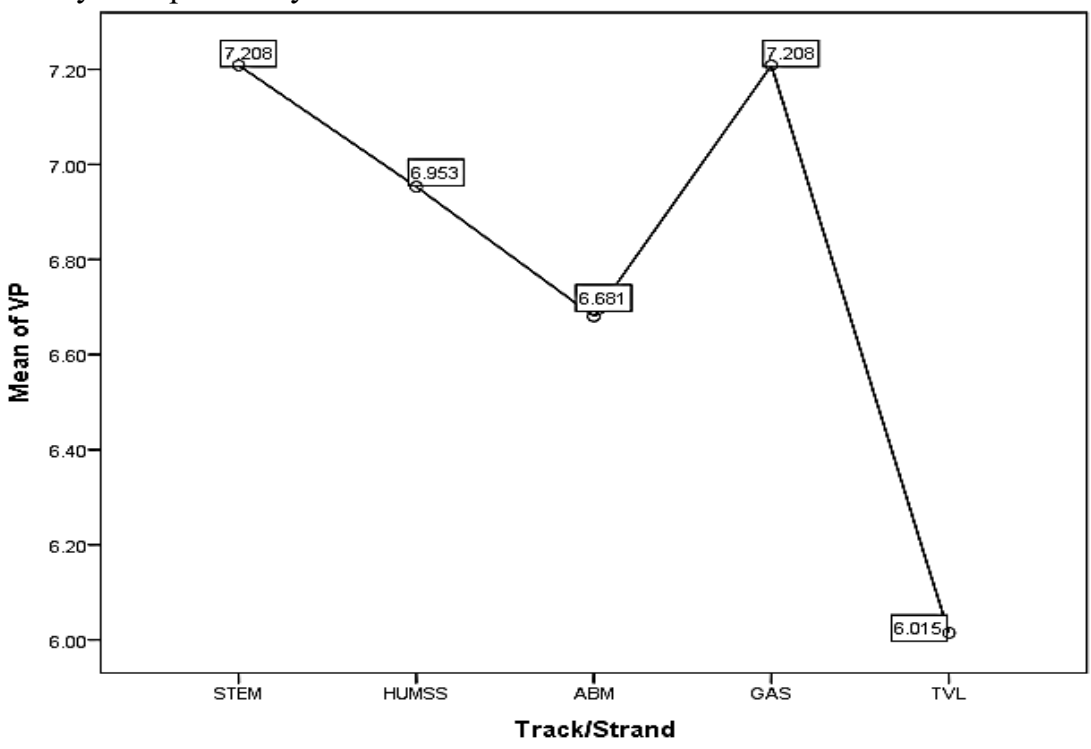

Figure 2.

Mean plots Verbal Persuasion Self Efficacy Component by Tracks/Strand

The figure shows that the self-efficacy, verbal persuasion component, of STEM students $(\bar{x}=7.21 ; n=33)$, is significantly higher than those of the TVL students $(\bar{x}=6.01 ; n=36)$. This implies that students enrolled in STEM received more encouragement from the people around them than those enrolled in TVL. Students regardless of 
their choice of tracks should receive an equal amount of encouragement to propel them to work and most importantly succeed in their academic endeavor. Thus, students from TVL should be encouraged further not just for the reason of boosting their confidence but as well as in the light of intrinsically motivating them to study.

\section{Conclusion and Recommendation}

First, Grade 11 students have a moderate self-efficacy in general. This implies that they possess a level of selfefficacy that will enable them to succeed; Second, for a homogenous group, age and self-efficacy is not associated; and Third, there exists an exciting phenomenon in self-efficacy i.e., merely belonging to a particular school and a specific track generates or boosts self-efficacy in one way or the other.

Based on the foregoing conclusions, the following recommendations are made: First, parents and the school should help support and boost the self-efficacy of students by exposing them to more activities were they would tend to master and succeed; by showing models of success like individuals who have excelled in the specific track/strand; by increasing verbal encouragement towards schooling; by providing mechanism to assist students in managing their stress and improve their study habits; and by keeping a healthy environment both in school and home. Second, a further study could be conducted considering a heterogeneous sample to determine the association between academic self-efficacy and age. Third, a further study could be conducted involving students in various tracks and school type and how it influences self-efficacy; on how self-efficacy influence choice of track/strand and school type; on what is occurring in the private and public schools highlighting verbal encouragement and vicarious experience and how it influence self-efficacy; and by looking into the actors who provide verbal encouragement to students both in home and school and as to which school type receive more verbal encouragement

\section{References}

Bandura, A. (2006). Guide for constructing self-efficacy scales. Self-efficacy beliefs of adolescents, 307-337.

Brown, L.J., Malouff, J.M., \& Shutte, N.S. (2013). Self-efficacy theory. Massachusetts: Jones \& Barlett Learning Fraenkel, J.R. \& Wallen, N.E. (2009). How to design and evaluate research in education. New York: McGrawHill Companies, Inc.

George, D., \& Mallery, P. (2003). SPSS for windows step by step: a simple guide and reference. 11.0 update (4th ed.). Boston: Allyn \& Bacon.

Hayden, J. (2009). Introduction to Health Behavior Theory. Burlington: Jones \& Bartlett Learning.

Kumar, R., \& Lal, R. (2006). The role of self-efficacy and gender difference among the adolescents. Journal of the Indian Academy of Applied Psychology, 249-254.

Lewallen, T. C., Hunt, H., Potts-Datema, W., Zaza, S., \& Giles, W. (2015). The whole school, whole community, whole child model: A new approach for improving educational attainment and healthy development for students. Journal of School Health, 85(11), 729-739. doi:10.1111/josh.12310.

Mateo, J. (2015, June 7). QC has the most senior high schools in MM. Retrieved October 5, 2016, from PhilStar Global: http:/www.philstar.com/metro/ 2015/06/07/ 1463037/qc-has-most-senior-high-schools-mm.

Pajares, F. (1996). Self-efficacy beliefs in academic settings. Review of educational research (66), 543-578.

Pajares, F., Hartley, J., \& Valiante, G. (2001). Response format in writing self-efficacy assessment: Greater discrimination increases prediction. Measurement and Evaluation in Counseling and Development, 38(4).

Pallant, J. (2004). SPSS survival manual: A step by step guide to data analysis using SPSS. Buckingham: Open University Press.

Rasmussen, M., \& Laumann, K. (2013). The academic and psychological benefits of exercise in healthy children and adolescents. European Journal of Psychology of Education, 28(3), 945-962.

Salvucci, S., Walter, E., Conley, V., Fink, S., \& Saba, M. (1997). Measurement error studies at the National Center for Education Statistics (NCES). Washington DC: U. S. Department of Education.

Schwarzer, R. (1992). Self Efficacy: Thought control of action. Washington, DC: Hemisphere

Tenaw, Y. A. (2013). Relationship between self-efficacy, academic achievement and gender in analytical chemistry at debre markos college of teacher education. AJCE.

Willeboordse, M., Jansen, M. W., van den Heijkant, S. N., Simons, A., Winkens, B., de

Groot, R. M., \& ... Oosterhoff, M. (2016). The healthy primary school of the future: Study protocol of a quasiexperimental study. BMC Public Health, doi:10.1186/s12889-016-3301-9.

Zhang, Z.-J., Zhang, C.-L., Liu, X.-M., Zhang, H., Wang, J., \& Liu, S. (2015). Relationship between self-efficacy beliefs and achievement motivation in student nurses. Chinese Nursing Research, 67-70. 